\title{
Lacrimal Duct Obstruction
}

National Cancer Institute

\section{Source}

National Cancer Institute. Lacrimal Duct Obstruction. NCI Thesaurus. Code C34757.

Blockage of the tear duct. 